\title{
Eocene-Oligocene cooling and the diversification of Hemidactylus geckos in Peninsular India
}

\author{
Aparna Lajmi ${ }^{\mathrm{a}, \mathrm{b}, *}$, Praveen K. Karanth ${ }^{\mathrm{a}}$ \\ ${ }^{a}$ Centre for Ecological Sciences, Indian Institute of Science, Bangalore 560012, Karnataka, India \\ ${ }^{\mathrm{b}}$ Institute of Evolution, Department of Evolutionary and Environmental Biology, University of Haifa, Haifa 3498838, Israel
}

\section{A R T I C L E I N F O}

\section{Keywords:}

Paleoclimate

Biogeography

Radiation

Aridification

South Asia

Gecko

\begin{abstract}
A B S T R A C T
The Eocene-Oligocene cooling marks a global shift towards a cooler and drier climate, concurrent with significant turnover in biota globally. In Peninsular India, palynological investigations suggest a shift from wet rainforest vegetation to dry and seasonal species during this period. However, the grassland and open habitats that dominate this region at present expanded relatively recently due to Late Miocene intensification of monsoon seasonality. We test the possible role of these climatic shifts in generating the dry habitat diversity of an endemic radiation of Hemidactylus geckos distributed in both wet and dry habitats, by investigating whether (a) the beginning of the diversification of dry habitat lineages overlap with the Eocene-Oligocene cooling or late Miocene aridification and (b) accompanied by an increase in diversification. Molecular data (two nuclear and two mitochondrial gene fragments) were generated for samples collected across Peninsular India, and along with previously published data, a time-calibrated phylogeny was reconstructed. Ancestral state reconstruction of dry and wet habitat states was carried out on the time-calibrated phylogeny and $\gamma$-statistics along with a test for diversity-dependent diversification utilized to examine the trend in lineage accumulation. Results show the ancestral node of this radiation to have a dry habitat state, which began diversifying between 39 and 32 million years ago, concurrent with the Eocene-Oligocene cooling. Furthermore, lineage diversification fit a diversitydependent model of diversification and the $\gamma$-statistics revealed an early increase in diversification followed by a slowdown later. The deep divergences of dry habitat lineages concurrent with the Eocene-Oligocene cooling suggest that this could have served as an ecological opportunity facilitating an early increase in lineage diversification of Hemidactylus in this region. These results suggest an ancient origin and long persistence of arid ecosystems in Peninsular India.
\end{abstract}

\section{Introduction}

Changing climate is a major driver of macroevolutionary dynamics (Erwin, 2009; Ezard et al., 2011). The Cenozoic era is marked by a global trend towards a cooler and drier climate, particularly two abrupt shifts in temperature-the Eocene-Oligocene cooling and Late Miocene aridification (Zachos et al., 2001). These changes in climate have influenced the diversification of biota across the globe (Mayhew et al., 2008; Morley, 2000; Prothero and Berggren, 2014; Zhang et al., 2012). Peninsular India and Sri Lanka support an extensive dry zone that formed during this period. However, the relative roles of these climatic shifts in shaping the diversity of dry habitats in this region are poorly understood. Phylogenetic reconstruction of evolutionary histories of organisms can aid in this endeavor. For example, with the help of timecalibrated phylogenies, plant groups specific to certain biomes have been studied to estimate the time of origin of these biomes (Becerra, 2005; Byrne et al., 2011; Davis et al., 2005; reviewed in Pennington et al., 2006; Richardson et al., 2001). In groups that have representative species in multiple biomes, such studies have given insights into what the ancestral biome was and the timing of biome shifts (reviewed in Donoghue and Edwards, 2014). However, few studies on animal taxa have used this framework (but see Marin et al., 2013; Agarwal and Ramakrishnan, 2017; Brennan and Oliver, 2017). Thus, one could test specific hypothesis regarding the ancestral state/biome of the organism or biome shifts, given the paleoclimate and the biome preferences of the organism.

Eocene-Oligocene cooling (EOC) is the most prominent climatic shift after the Cretaceous (Prothero, 1994). Following the warm and humid early Eocene Climatic Optimum 52-50 million years ago (Mya), the temperature began to decline and the trend towards cooler

\footnotetext{
* Corresponding author at: Institute of Evolution, Department of Evolutionary and Environmental Biology, University of Haifa, Haifa 3498838, Israel.

E-mail address: aparna@evo.haifa.ac.il (A. Lajmi).
} 


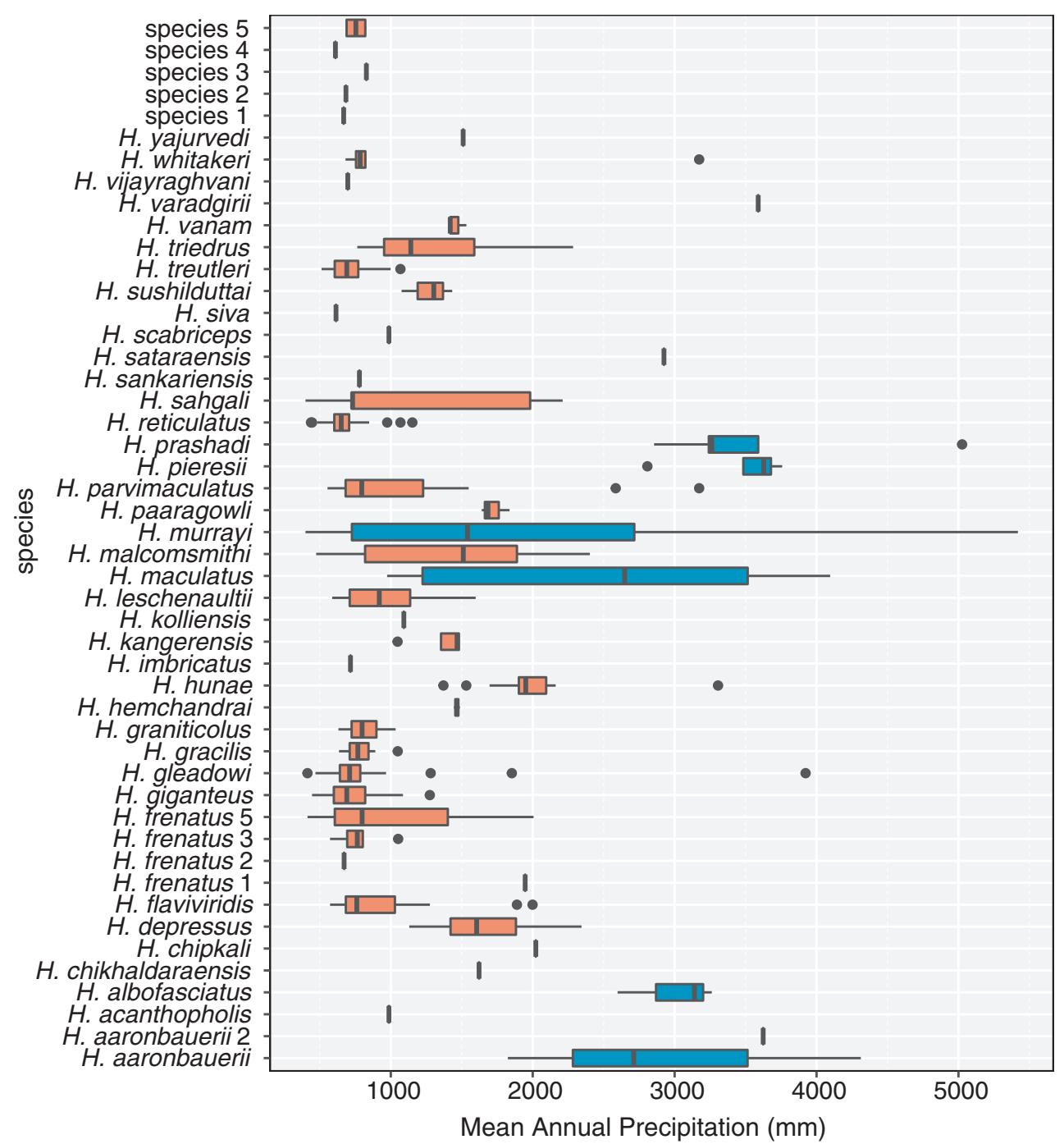

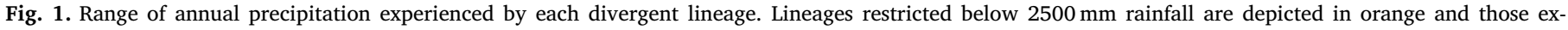

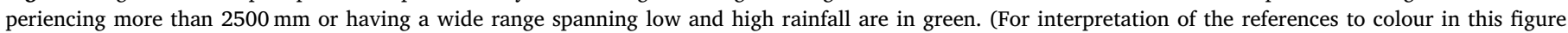
legend, the reader is referred to the web version of this article.)

conditions lasted for 17 million years with a rapid drop in temperature at the Eocene-Oligocene boundary 33.7 Mya (Zachos et al., 2001). This period of a rapid decrease in temperature is called the Eocene-Oligocene transition. The cooling starting from late middle-Eocene up until early Oligocene resulted in increased aridification (Abels et al., 2010; Dupont-Nivet et al., 2007; Hoorn et al., 2012; Kargaranbafghi and Neubauer, 2017; Passchier et al., 2013) and temperature seasonality (Hren et al., 2013; Ivany et al., 2000; Wade et al., 2012). This led to a mass biotic turnover of terrestrial as well as marine flora and fauna from warm and humid adapted to more cold- and dry adapted taxa, across this time period (Brennan and Oliver, 2017; Meng and McKenna, 1998; Prothero, 1994; Champion and Seth, 1968; Stadler, 2011; Sun et al., 2014; Zhang et al., 2012).

The cold period was interrupted by a relatively warm temperature from the late Oligocene up until the middle Miocene 26-15 Mya (Zachos et al., 2001). The cooling and aridification after the mid-Miocene had a profound influence on the diversification of biota in Australia, Eurasia, as well as Africa (Cerling et al., 1997; Richardson et al., 2001; Tang and Ding, 2013). Although C4 grasses evolved 35 Mya, their range expanded considerably in the Late Miocene 8-6 Mya, which facilitated the opening up of forested habitats (Edwards et al., 2010; Edwards and Smith, 2009; Pound et al., 2012). This led to a global turn over from forest-dwelling to open habitat organisms that occupied this novel habitat (Fortelius et al., 2006).

The Indian subcontinent also experienced these climatic shifts and associated turnover of flora. Palynological studies reveal that while the early Eocene harbored the richest and most diverse palynomorph assemblages, there was a marked reduction in the diversity of palynomorphs during the EOC. After this period, regional differences in their assemblages become more apparent (Morley, 2000; Prasad et al., 2009). The Late Eocene also saw the immigration of several plant taxa that indicate the development of drier or more seasonal climate (Morley, 2000). By early Miocene ( 23 Mya) the monsoonal seasonal climate became more pronounced in Peninsular India (Clift et al., 2008). The last phase of intense aridification occurred between 11 and 7 Mya, concurrent with the global Miocene aridification, leading to the establishment of open habitats and grasslands especially in the Northwestern Indian subcontinent (Molnar and Rajagopalan, 2012). Today, much of Peninsular India can be characterized as a dry zone that receives less than $2500 \mathrm{~mm}$ average rainfall annually (Karanth, 2003). The wet evergreen forests, that covered most of the Indian plate during Paleocene, are today largely restricted to the Western Ghats and very few pockets in Sri Lanka (Prasad et al., 2009). These shifts in climate and the concomitant changes in vegetation are bound to have influenced the diversification of many taxa. Thus, Peninsular India and Sri Lanka provide an ideal setting to examine the role of past climate in the 
diversification of biota.

Little is known about how these early climatic shifts might have shaped the current diversity and distribution of Indian fauna. A phylogenetic study on wet zone restricted Gegeniophis caecilian revealed that the eastern and western lineage diverged around 37.5 (45.1-30.2) Mya, and the establishment of dry climate in the intervening areas was hypothesized to have caused this separation (Gower et al., 2016). During the late Miocene, dry and open grassland restricted lizards such as Sitana and Ophisops show increased diversification (Agarwal and Ramakrishnan, 2017; Deepak and Karanth, 2018), suggesting prevalence and expansion of open habitats during the late Miocene. Fossorial snakes that have a preference for mesic habitats showed a decrease in diversification and turnover rate from late Miocene to present (Cyriac and Kodandaramaiah, 2017). Apart from these handful of studies, our understanding of the evolution of dry habitat biota is limited.

Peninsular India and Sri Lanka harbor a radiation of Hemidactylus geckos, referred here as the Indian radiation, that is largely restricted to this region (Bansal and Karanth, 2010; Bauer et al., 2010b). Most species of the Indian radiation are distributed in the dry zone of Peninsular India, with a few distributed in areas with higher rainfall of $>2500 \mathrm{~mm}$ mean annual precipitation, particularly in the Western Ghats (Fig. 1). Additionally, the Indian radiation began diversifying during the Late Eocene-Early Oligocene (41-28 Mya; Lajmi et al., 2019). This overlaps with the time when Peninsular India was covered with tropical forest to the appearance of drier flora. Thus, the Indian radiation is an ideal model system to investigate whether the EOC or the late Miocene aridification generated the current dry habitat diversity. In this study, the EOC hypothesis predicts (a) the ancestor/ ancestors of dry habitat lineages to overlap with the EOC and (b) a constant diversification rate or an early increase in diversification rate coinciding with the EOC. Under this hypothesis, the wet habitat lineages would have evolved more recently from dry habitat ancestors. On the other hand, the Late Miocene aridification hypothesis predicts (a) the ancestor/ancestors of dry habitat lineages to overlap with the late Miocene and (b) increase in diversification rates to coincide with late Miocene aridification. Therefore, under this hypothesis, the basal nodes of the Indian radiation would be wet habitat and the dry habitat lineages would have evolved during the late Miocene. Both these hypotheses are rejected if the evolution of dry habitat ancestor (along with the credible interval) does not overlap with either of these climatic shifts. We test these hypotheses (Fig. 2) using ancestral state reconstruction on a time-calibrated phylogeny along with diversification analyses.

The Indian radiation includes 39 described species. However, a large part of the diversity in this radiation has not been described, as the dry zone of Peninsular India is largely unexplored. Therefore, through intensive taxon sampling, we first identify putative species using species delimitation methods and then test the hypotheses stated above using a hypothesis testing framework.

\section{Material and methods}

\subsection{Taxon sampling and molecular work}

Opportunistic sampling was carried out across the distribution range of this radiation in Peninsular India (Table S2 in Appendix S1). Tissue samples were preserved in 100\% alcohol and DNA was extracted using Qiagen DNeasy blood and tissue kit. Four fragments of DNA were PCR amplified-two partial mitochondrial genes cytochrome $b$ (cyt $b$; $307 \mathrm{bp}$ ) and NADH dehydrogenase 2 (ND2; $981 \mathrm{bp}$ ) and two partial nuclear genes, Recombination Activation Gene1 (RAG1; 1044 bp) and Phosducin (PDC; $395 \mathrm{bp}$ ) amounting to $2727 \mathrm{bp}$. PCR protocol was as per Bansal and Karanth (2010) and Bauer et al. (2010). These four markers have been used extensively in phylogenetic studies of the genus Hemidactylus and are known to resolve the relationships within the Indian radiation (Bansal and Karanth, 2010; Bauer et al., 2010b; Lajmi et al., 2019). Our sampling included all the described species from the Indian radiation except $H$. peiresii from Sri Lanka which is believed to be sister to $H$. depressus.

\subsection{Phylogenetic analysis}

Sequence data from all four markers mentioned above was used for phylogenetic reconstruction. Previously published sequence data of Indian and Sri Lankan species were included from Bauer et al. (2010), Bansal and Karanth (2010), Lajmi et al. (2019), Agarwal et al. (2019), Chaitanya et al. (2018), Mirza et al. (2018), Mirza and Raju (2017), Srikanthan et al. (2018) (Table S2 in Appendix S1). Representatives of other major Hemidactylus clades were also incorporated in the analyses, along with three species of Cyrtodactylus, which were used as outgroup (based on Gamble et al., 2012; Pyron et al., 2013). There were 1617 variable sites and 1356 parsimony informative sites in the dataset. Individual gene sequences were aligned in MEGA 5.2.2 (Tamura et al., 2011) using clustalW (Thompson et al., 1994) and then concatenated. PartitionFinder v1.1.1 (Lanfear et al., 2012) was used to find the best partitioning scheme and appropriate models of sequence evolution (Table S1 in Appendix S1). Phylogenetic trees were constructed using
A

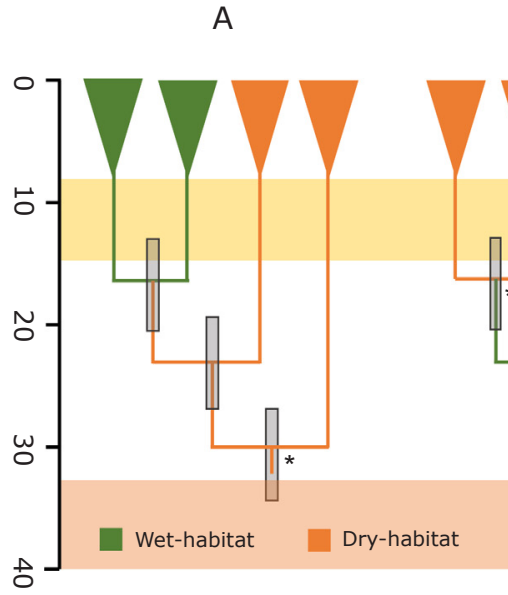

B C 
maximum likelihood (ML) approach implemented in RAxML HPC 7.4.2 (Stamatakis, 2006) using the graphical interface raxmlGUI v1.3.1 (Silvestro and Michalak, 2012) and Bayesian inference in MrBayes 3.2.1 (Ronquist et al., 2012). In RAxML, a thorough ML search with 1000 bootstraps for 10 runs was carried out. The analysis in MrBayes was carried out for 5 million generations sampling every 500 generations. The likelihood values of the two runs were visualized in Tracer v1.6 (Rambaut et al., 2014) to check for stationarity. To evaluate convergence across runs the standard deviation of split-frequency of $<0.01$ was used. The initial $25 \%$ of sampled trees were discarded as 'burn-in' before constructing the consensus tree.

\subsection{Species delimitation}

DNA sequence data from nuclear marker RAG1 and PDC, and mitochondrial marker cyt $b$ was used for species delimitation. Two methods were used to identify divergent lineages within the Indian radiation - the single locus multi-rate Poisson Tree Processes (mPTP; (Kapli et al., 2017) using the cyt $b$ data and multilocus Bayesian species delimitation and species tree estimation using the program BPP v3.3 (Yang and Rannala, 2014) on the cyt $b$, RAG1, and PDC datasets. ND2 was not be used for species delimitation as many samples lacked this data. mPTP is an improved method to the previously published PTP and bPTP methods as it tries to accommodate different levels of intraspecific genetic diversity and differential sampling of each species. The partitioned mitochondrial cyt $b$ dataset was used for building the ML phylogenetic tree in raxmlGUI v1.3.1 (Silvestro and Michalak, 2012). This analysis was run for 100 million generations in 4 independent runs, and $25 \%$ of the initial samples were discarded as burn-in. Multilocus Bayesian method BPP (Yang, 2015) requires a priori species hypothesis and the MPTP output along with the currently known described species was used as the input for the Bayesian analysis. The BPP analysis was done on each individual clade separately as the program cannot handle a large number of "species". A combination of different gamma prior (G) was used to account for different demographic scenarios of large and small population size $(\theta s)$ and deep and shallow divergence times $\left(\tau_{0}\right)-\theta=G(1,10)$ and $\tau=G(1,10), \theta=G(1,10)$ and $\tau=G(2,2000)$, $\theta=G(2,2000)$ and $\tau=G(1,10)$, and $\theta=G(2,2000)$ and $\tau=G(2$, 2000) as employed by (Leache and Fujita, 2010; Huang and Knowles, 2016). Each analysis was run twice for 1 million generations with parameters sampled every 2 generations and a burnin of 80,000 generations.

\subsection{Divergence date estimation}

Divergence dates were estimated in a Bayesian framework with the program BEAST v1.8.3 (Drummond et al., 2012) using a combined dataset consisting of the two nuclear genes, RAG1 and PDC, and the mitochondrial gene ND2. We used one representative of each of the divergent lineage identified to build the dated phylogeny. This ensured that the data across all the markers were near complete for these lineages. Additional outgroup taxa were added as mentioned in Agarwal et al. (2014b), which were used to calibrate the phylogeny. The dataset was partitioned and models of sequence evolution were applied as proposed by PartitionFinder v1.1.1 (Lanfear et al., 2012). The analysis was constrained to obtain the same topology as the ML tree. A relaxed uncorrelated lognormal distribution and Yule process tree prior were used. Five calibration points were used as in previously published studies (Gamble et al., 2008; Heinicke et al., 2011; Nielsen et al., 2011; Agarwal et al., 2014a; Agarwal and Karanth, 2015) (Table S4 in Appendix S1). The Markov Chain Monte Carlo (MCMC) was run for 100 million generations, sampling every 10,000 generations and estimated sample sizes $(>200)$ calculated in Tracer v1.6 to ensure appropriate chain length. The initial $25 \%$ of the trees were discarded as burnin. Two independent analyses were run and the trees of the two runs were combined using the program Logcombiner v1.8.3 included in the BEAST package. A maximum clade credibility (MCC) tree with median heights was generated in TreeAnnotator v1.8.3. To test the sensitivity of the age estimates to the calibration priors, we ran five independent analyses by dropping each of the five calibration points at a time.

\subsection{Ancestral state reconstruction}

To understand the rainfall regimes in which each lineage was distributed, mean annual precipitation (MAP; BIO12) data were extracted from WorldClim Version 2 (Fick and Hijmans, 2017) for a total 550 locations (Fig. S1). To this end, location data from fieldwork and published literature (Agarwal et al., 2019, 2011; Bauer et al., 2010b; 2010a; Chaitanya et al., 2018; Dandge and Tiple, 2015; Gaikwad et al., 2009; Giri and Bauer, 2006; Giri, 2008; Giri and Bauer, 2008; Giri et al., 2017; Lajmi et al., 2019; 2016; Mirza and Sanap, 2014; Mirza, 2018; Mirza et al., 2018, 2017; Mirza and Raju, 2017; Murthy et al., 2014; Srikanthan et al., 2018; Srinivasulu et al., 2018, 2014) was collected for 48 divergent lineages in the Indian radiation. No information on species from the Indian radiation was available on Global Biodiversity Information Facility (GBIF; http://www.gbif.org/) except in the case of human commensal species from outside Peninsular India and Sri Lanka, which are likely to have been moved around recently. The range of MAP experienced by each divergent lineage was visualized with a box plot to determine whether they are restricted to dry or wet zone (Fig. 1). Similarly, all the other 18 bioclimatic variables were also examined post-hoc.

Tropical evergreen, semi-evergreen to moist deciduous forests in Peninsular India experience MAP of $>2500 \mathrm{~mm}$ (Karanth, 2003; Prasad et al., 2009; Champion and Seth, 1968). Whereas areas that experience $<2500 \mathrm{~mm}$ rainfall are largely covered with dry deciduous to scrub forests as well as open savanna habitats. Therefore, all lineages that experienced $>2500 \mathrm{~mm}$ of MAP were considered as wet habitat lineages. Fig. 2 also shows a clear trend where most lineages found in the dry zone experience $<2500 \mathrm{~mm}$ MAP. Therefore, lineages restricted to this rainfall conditions were categorized into dry habitat lineages. However, no such trend was observed with respect to other bioclimatic variables that we examined. Moreover, a priori data to categorize these variables is not known. MAP Ancestral state reconstruction was employed to determine whether the ancestral state of the Indian radiation was wet habitat or dry habitat lineage. MAP was used as a continuous variable as well as discretized by categorizing these lineages into dry and wet habitat.

The time-calibrated phylogeny of the Indian radiation was used for ancestral state reconstruction. For discrete character mapping of dry and wet habitat states, we first tested between four different rate transition models to find the best fit model using the function fitMk 1 . equal rates (ER) model 2. all rates different (ARD) 3. and 4. the two possible irreversible models. The best fitting model was chosen based on AIC scores. For the reconstruction of the discrete traits, 1000 stochastic character map simulations were generated using the function make.simmap in the phytools package v0.6-00; (Revell, 2012) for R team (2014) using the rate transition matrix. For continuous character mapping, we used mean values of MAP raw as well as log-transformed values as the trait value. We compared the model fit between a Brownian motion (BM) and Ornstein-Uhlenbeck (OU) models using Akaike Information Criterion (AIC) scores in the $\mathrm{R}$ package Geiger (Harmon et al., 2008). The ancestral state was estimated using the function fastAnc in the $\mathrm{R}$ package phytools, assuming the best fitting model. The reconstructions were then visualized using the functions contMap and phenogram.

\subsection{Diversification analyses}

Gamma statistics ( $\gamma$-test; Pybus and Harvey, 2000) was used to understand the trend in lineage accumulation through time on 1000 
trees sampled from the posterior distribution of the BEAST run. When lineages follow a pure-birth model of diversification, $\gamma<0$ implies that lineages have accumulated early in the history of the clade while $\gamma>0$ means accumulation of lineages closer to the tips. The $\gamma$ distribution of 1000 trees from this data was compared with that of 10,000 trees simulated under a pure birth model. To make sure that the slowdown in diversification rates towards the tips is not due to lack of time for speciation (protracted speciation; Etienne and Haegeman, 2012) or failure to identify cryptic lineages, we excluded the last 2 million years of branches from the tree after which there are no speciation events, and recalculated $\gamma$ statistics. This analysis was also done using the package Phytools v0.6-00 (Revell, 2012) in R team (2014). Given the caveats of $\gamma$-statistics (Fordyce, 2010), we also tested for diversity-dependent diversification using the R package DDD (Etienne and Haegeman, 2012). DDD is a maximum likelihood approach which allows us to fit a diversity-dependent model and contrast it with a diversity-independent constant rate model. We used a likelihood ratio test to compare these two models. We refrained from using other statistical programs to estimate rate shifts since most of these rely on large phylogenetic trees for a robust estimate of diversification rate and rate shifts.

\section{Results}

Molecular data from a total of 224 samples, including published data, were analyzed. Maximum likelihood and Bayesian phylogenies of the concatenated dataset revealed similar topologies. The Indian radiation was retrieved with high ML and BI support (Fig. 3), although its relationship with other Hemidactylus could not be ascertained due to low support. The Indian radiation has three major well-supported clades - clade 1, 2 and 3-similar to Lajmi et al., 2019, Bansal and Karanth (2010) and Bauer et al. (2010). The phylogeny unveiled high genetic diversity ( $>12 \%$ in cyt $b$ ) within a few species, which are likely to be cryptic species complexes- $H$. reticulatus and $H$. frenatus. Information on sampling location, species, museum ID and Genbank numbers are reported in Table S2 in Appendix S1.

The mPTP analysis estimated 43 divergent lineages within the Indian radiation (Fig. 3) based on the cyt $b$ phylogeny. While most of the described species were correctly identified to be distinct (24 species), some clades with high genetic diversity were split into multiple divergent lineages $-H$. reticulatus, $H$. frenatus, and $H$. aaronbaueri. In four cases two or more distinct species were grouped together- $H$. malcolmsmithi $+H$. parvimaculatus, $H$. gracilis $+H$. sataraensis $+H$. imbricatus $+H$. albofasciatus, $H$. hemchandrai $+H$. yajurvedi, and $H$. treutleri $+H$. varadgirii. However, all these species are morphologically distinct (Bauer et al., 2008; Dandge and Tiple, 2015; Gaikwad et al., 2009; Giri and Bauer, 2008; Lajmi et al., 2016; Murthy et al., 2014). The 43 divergent lineages identified by MPTP and the additional described species were taken as input for the Bayesian analysis. This approach supported 41 species. It recognized all the described species except in case of $H$. parvimaculatus and $H$. malcolmsmithi, and, $H$. reticulatus and $H$. vijayraghavani, where two species were grouped into one. These were considered to be separate lineages for further analysis. $H$. parvimaculatus and $H$. malcolmsmithi differ considerably in morphology and appear to have disjunct geographical distributions (Lajmi et al., 2016). However, these two cases need to be investigated more thoroughly. Furthermore, three recently described species, $H$. kolliensis, $H$. sankariensis, and H. chikhaldaraensis (Agarwal et al., 2019) could not be included in the species delimitation as only ND2 data was available for these species. They were also considered distinct lineages for further analysis. Thus, 48 divergent lineages were identified in the Indian radiation (Fig. 3) and the posterior probabilities associated with each of these potentially distinct species are given in Table S3 in Appendix S1.

The time-calibrated phylogeny revealed that the diversification in this radiation began 39-32 Mya (Fig. 4a). For further analysis, this tree was used (complete dated phylogeny in Appendix S2). The overall

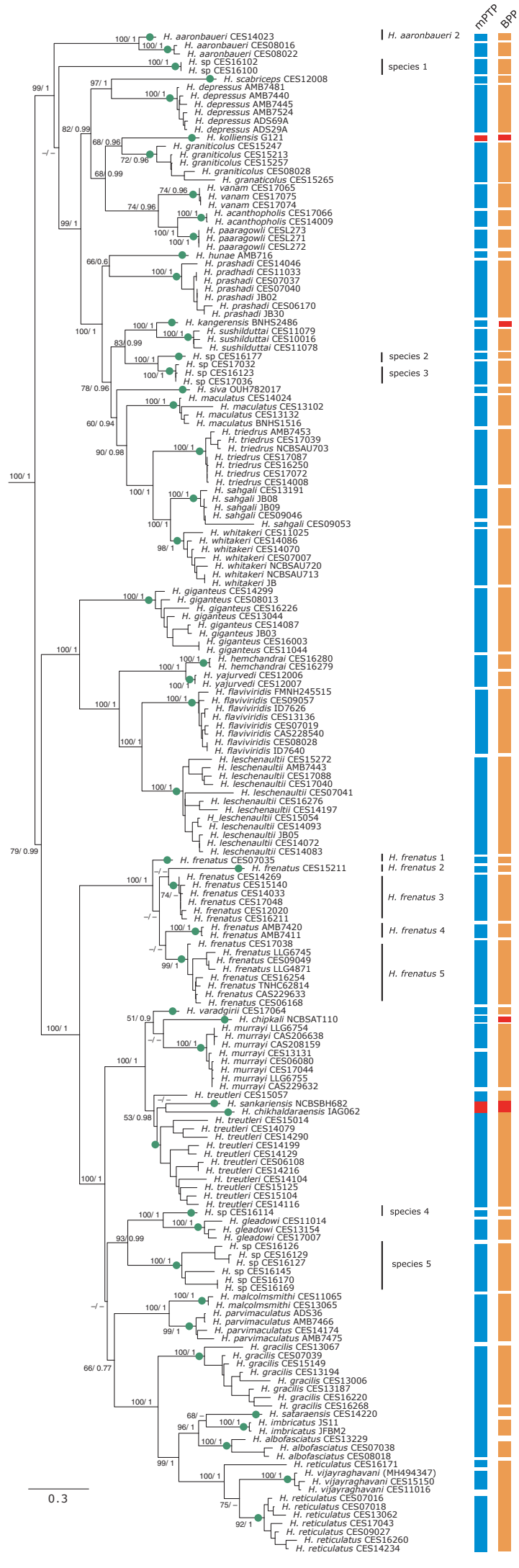

(caption on next page)

results do not change when the calibration priors are excluded one at a time from the analysis. We also estimated the divergence dates after dropping the mitochondrial 3rd position. The 95\% HPD of the most 
Fig. 3. Maximum likelihood phylogeny of the Indian radiation of Hemidactylus geckos with concatenated data (2727 bp). Values at the nodes denote maximum likelihood bootstrap support and posterior probability. Divergent lineages identified by MPTP are depicted in blue and BPP results are indicated in orange, with missing taxa for the analysis in red. Green dots on each of the branches represent candidate lineages chosen for further analysis. (For interpretation of the references to colour in this figure legend, the reader is referred to the web version of this article.)

recent ancestor of the Indian radiation overlapped with the EOC in all the analyses. The results of these analyses are mentioned in Table S5 in Appendix S1. The mean annual precipitation data for each divergent lineage showed that 38 out of the 48 species experienced $<2500 \mathrm{~mm}$ of MAP, while nine species were distributed in the wet zone (Fig. 1). Three lineages from the wet zone showed comparatively large variation in the amount of annual precipitation they experience. For discrete character mapping, the ER model was chosen based on AIC scores which fit marginally better than the irreversible model (dry to wet habitat only; $\Delta$ AIC $=0.08)$. The dry habitat phenotype was retrieved as the ancestral state in the discrete character mapping analysis with a probability of 0.99 (Fig. 5a). BM model fit the dataset better than OU model for the MAP raw as well as log-transformed data, and the BM model was used for the ancestral state reconstruction. The continuous trait mapping of raw MAP gave an ancestral state value of $1381 \mathrm{~mm}$ for the Indian

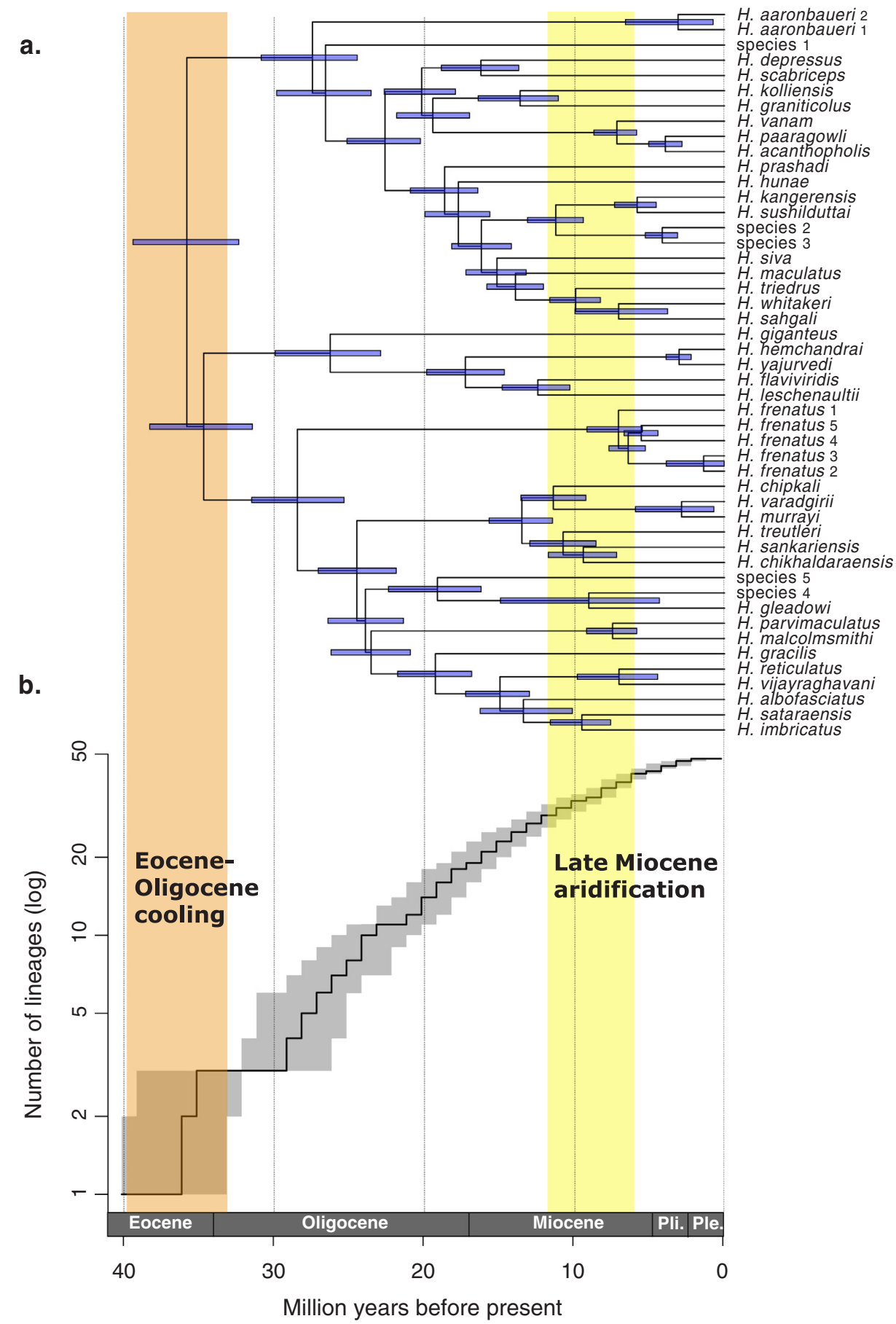

Fig. 4. a. Time-calibrated phylogeny of the Indian radiation along with credible intervals associated with each node. b. Lineage through-time plot with the black line showing the median age of lineages and the grey area denoting credible interval drawn from the posterior distribution. 
a.

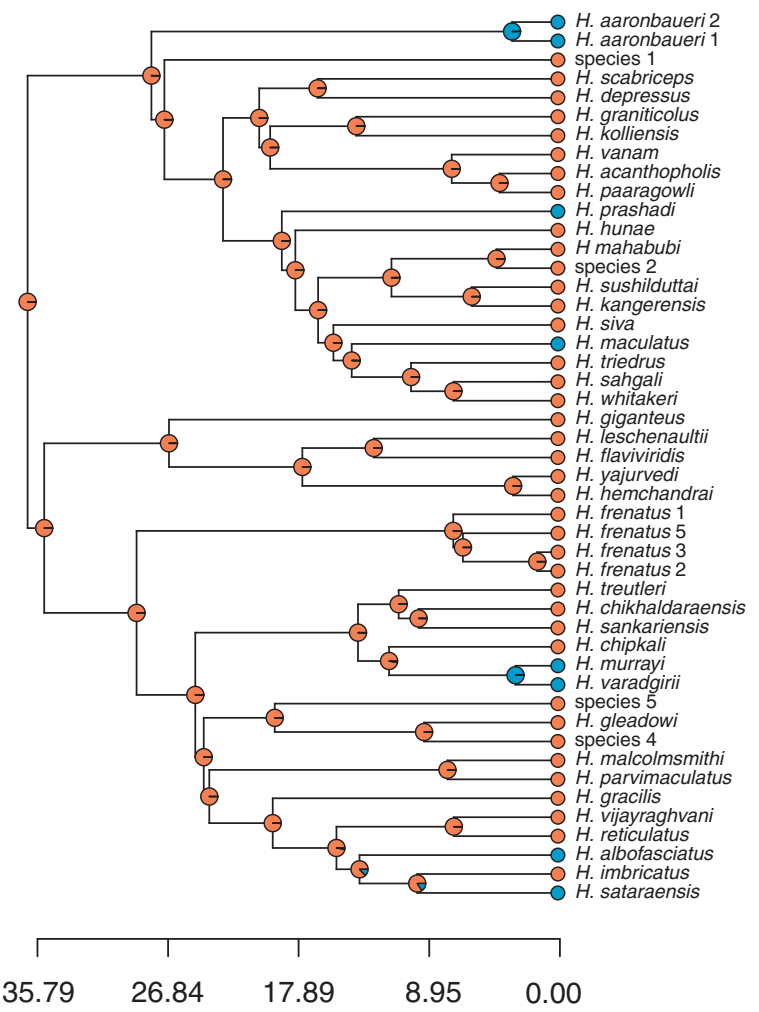

b.

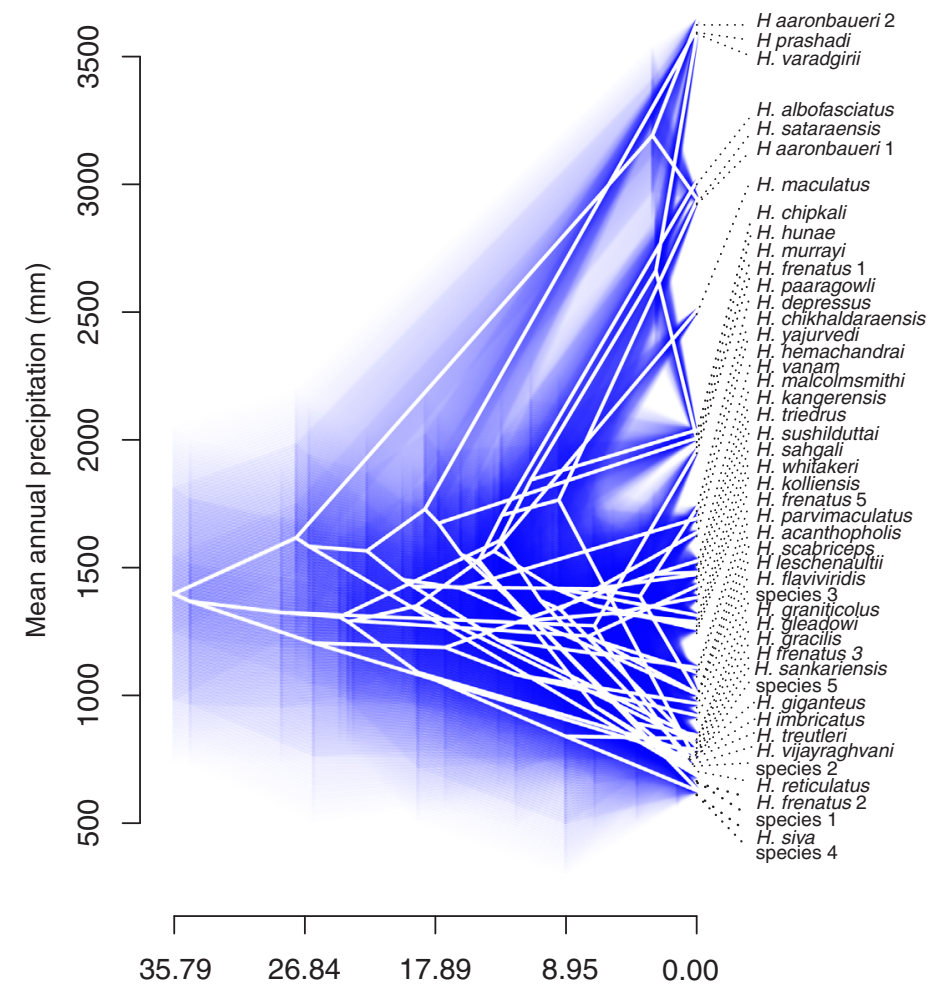

Million years before present

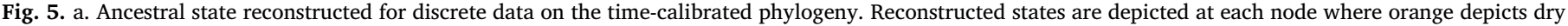

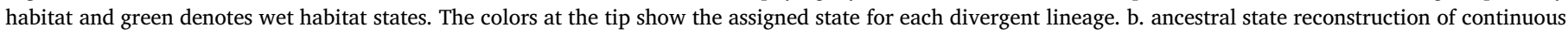

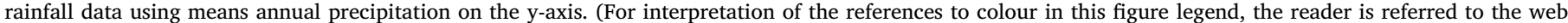
version of this article.)

radiation with a credible interval ranging from 428 to $2333 \mathrm{~mm}$. The ancestral state with log-transformed value was found to be $1176 \mathrm{~mm}$ with a credible interval of $617-2244 \mathrm{~mm}$. Although large, the credible interval lies below $2500 \mathrm{~mm}$ (Fig. 5b). Lineages have shifted from low to high rainfall regimes more recently and independently at least six times (Fig. 5a).

The gamma value of 1000 trees from the posterior distribution ranged from -4.49 to -2.85 (median -3.45 ; $p$-value $<0.001$; Fig. 4b). All trees were significantly different from the null distribution of simulated trees. Removing the last two million years increased the $\gamma$ values $(-2.47, p$-value 0.014$)$, but it was still significantly lower than null suggesting that slowing down of diversification is unlikely to be due to lack of time for recent speciation. The MCC tree of Indian radiation fit diversity-dependent diversification model better, further confirming slow-down of diversification rates later. The loglikelihood of the diversity-dependent model $(-139.74)$ was greater than that of a constant rate model $(-145.78)$.

\section{Discussion}

We examined whether the EOC or late Miocene aridification led to an increase in the dry habitat diversity of Hemidactylus geckos in Peninsular India and Sri Lanka. We tested these hypotheses by reconstructing a time-calibrated phylogeny with near complete taxon sampling and used ancestral state reconstruction of dry and wet habitat states to investigate whether the dry habitat ancestor evolved during the EOC or late Miocene aridification. The trend in lineage accumulation was also examined to test if the increase in diversification rate was concurrent with the evolution of dry habitat ancestor. We found that the reconstructed ancestral state of the Indian radiation, 39-32 Mya, was a dry habitat state and the credible interval of this node overlaps with the EOC. Furthermore, the trend in lineage diversification showed an early increase in diversification rate and fit diversity-dependent diversification. Thus, the hypothesis proposing the role of EOC in facilitating the dry habitat diversity in Peninsular India cannot be rejected. On the other hand, late Miocene aridification hypothesis can be rejected as the evolution of dry habitat ancestor does not coincide with this event. Moreover, there is a slowdown in diversification rates during the Miocene. These results suggest that the EOC played a role in generating the dry habitat diversity of Hemidactylus in Peninsular India.

We first performed lineage delimitation, as a robust and complete phylogeny is prerequisite to test these hypotheses in a phylogenetic framework. Given the underestimation of alpha diversity in the tropics, we first addressed this issue through broad sampling followed by using two coalescent-based methods for species delimitation. More thorough sampling focusing on each of the species complexes, along with species delimitation using multiple lines of evidence is required to establish the species status of the lineages delimited in this study. If these are indeed valid species, this would be a substantial increase in the species diversity of Hemidactylus geckos from the Indian radiation (from 39 species).

\subsection{Dry and wet habitat lineages}

The mean annual precipitation (MAP) data extracted for each divergent lineage revealed that most of them were distributed in low rainfall conditions of $<2500 \mathrm{~mm}$ MAP. Additionally, many lineages were restricted to $<1000 \mathrm{~mm}$ MAP. While confined geographical 
distribution could result in a narrow range of precipitation in some lineages, many species like $H$. giganteus, $H$. gleadowi, $H$. parvimaculatus, $H$. flaviviridis, $H$. treutleri, $H$. gracilis, and $H$. reticulatus are widely distributed. In fact, $H$. parvimaculatus and $H$. flaviviridis are human commensal species. These species often disperse widely through humanmediated dispersal (Carranza and Arnold, 2006) and therefore, would be expected to span different rainfall conditions. Yet, all these species are restricted to the dry zone, suggesting the sensitivity of dry habitat species to higher precipitation. Another explanation for low Hemidactylus diversity in the wet zone could be that the pre-established fauna of the wet zone competitively excluded Hemidactylus. A total of six lineages were restricted to areas with $>2500 \mathrm{~mm}$ MAP. These species are present only in the wet zone and experience little variation in precipitation. This could be a result of one or more factors-inability to cope with the dry climate, geographic barrier restricting species to a smaller area in the wet zone (in case of $H$. sataraensis and $H$. albofasciatus), and/ or paucity of sampling (in case of $H$. varadgirii and $H$. aaronbaueri 2).

Other than species restricted to wet or dry habitats, three species were distributed in a wide range of rainfall conditions, namely $H$. murrayi, $H$. maculatus, and $H$. aaronbaueri. These species were categorized as wet habitat species in the ancestral state reconstruction. While this could have implications on the ancestral state, coding these species as wet and dry would result in higher support for an ancestral state of dry habitat species and will not change the overall pattern. This would further strengthen the argument that the ancestral lineage of this radiation was a dry habitat species. To avoid biased outcomes resulting from the inaccurate categorization of species to wet and dry habitat, we also used MAP as a continuous trait. Nevertheless, it must be noted that when lineages are assigned to wet or dry habitat, there is an implicit assumption that these lineages are adapted to these conditions. However, these "traits" have not been measured on the organism.

\subsection{Diversification shaped by drying climate}

The ancestral state reconstruction of discrete as well as continuous data revealed the dry habitat state to be the reconstructed ancestral state at the basal node of the Indian radiation. Furthermore, the wet habitat lineages have evolved independently multiple times relatively recently. The dry habitat ancestral lineage began diversifying 39-32 Mya, soon after the Indian plate collided with Asia. The docking of the Indian plate with Asia is proposed to have facilitated the dispersal of Hemidactylus into India (Bansal and Karanth, 2013). The change in climate during the EOC from humid to a more arid environment in Peninsular India could have provided a conducive environment for these geckos. Moreover, this region was yet to be occupied by other dry habitat lizard taxa which could have been potential competition. These factors could have served as an ecological opportunity for a dry habitat preferring ancestor, giving rise to the observed lineage accumulation pattern. Most of this early diversification in the Indian radiation seems to have occurred in Peninsular India, with dispersals into Sri Lanka only after early to mid-Miocene. Moreover, most of the dry habitat Hemidactylus diversity of Sri Lanka, which is a subset of the Indian Hemidactylus, is a result of relatively recent range expansion from Peninsular India (Lajmi et al., 2019). Although the deep divergences of dry habitat lineages overlapping the EOC point towards the persistence of dry climate in Peninsular India, the occurrence of dry habitats in Sri Lanka during this period remains unclear.

Given that the subcontinent has experienced a reduction of forest cover through the Cenozoic (Morley, 2000), there could have been extinctions of wet habitat lineages of Indian radiation. This could influence the ancestral state reconstruction, as the phylogenetic reconstruction here accounts for only extant lineages. However, most extant species of the genus Hemidactylus, which has a global distribution across the tropics and sub-tropics, are distributed in dry forest or open habitats. Therefore, it is likely that the ancestral lineage of the
Indian radiation that arrived on the Indian plate was a dry habitat species. Understanding the niche preferences of the sister clade could also shed light on this aspect. However, the sister clade of the Indian radiation is not known as the higher-level phylogeny of this genus is not yet resolved. Climate could have directly influenced diversification by providing conducive environment and/or could have indirectly influenced by facilitating diversification of certain kind of vegetation (giving rise to a new niche), diversification of prey species, and/or extinction of competition. Moreover, multiple factors other than climate could have facilitated the diversification of the Indian radiation, such as topographic and/or microhabitat heterogeneity (Deepak and Karanth, 2018; Vijayakumar et al., 2016), which needs detailed investigation.

The disparity in the number of dry and wet habitat species in the Indian radiation is not surprising as lizards often exhibit higher richness in arid regions, unlike most other vertebrates (Powney et al., 2010; Roll et al., 2017; Wiens et al., 2013). An investigation of diversification pattern across major squamate lineages in Australia dated the crown ages of these lineages to be after the Eocene (Oliver and Hugall, 2017). Particularly in pygopodoid lizards, the arid environment is thought to have facilitated the diversification of these lizards (Brennan and Oliver, 2017). Although squamates have a much deeper history, most of the diversification in the Australian arid zone is associated with the Miocene aridification.

The diversification pattern of the Indian radiation fits a diversitydependent model. Such pattern of diversification has been reported in adaptive radiations (Burbrink et al., 2012; Wagner et al., 2014) as well as several continental radiations (Phillimore and Price, 2008; Rabosky, 2013; Rabosky and Lovette, 2008a; Wagner et al., 2014). The slowdown in diversification rate is often proposed to be a result of ecological limits on resources that could lead to an equilibrium between speciation and extinction processes (Rabosky and Hurlbert, 2015). This decrease in diversification rates could be a result of decreasing speciation rate or increasing extinction rate. Rabosky and Lovette, 2008b demonstrate that phylogenies with a later slowdown in diversification rates result from decreasing speciation rate rather than an increasing extinction rate. In Peninsular India, diversification in other lizards such as Sitana and Ophisops inhabiting the dry zone increased relatively recently during the Late Miocene (Agarwal and Ramakrishnan, 2017; Deepak and Karanth, 2018). The intensification of monsoon seasonality and aridification during this period is proposed to have led to the establishment of savanna habitats, which facilitated increased diversification in these open habitat lizards. Many species of the Indian radiation are specific to these open habitats and grasslands. The clade of terrestrial geckos consisting of $H$. reticulatus, $H$. sataraensis, $H$. imbricatus, $H$. gracilis, $H$. vijayraghavani, and $H$. albofasciatus, began diversifying during this period. The overall trend of decrease in lineage accumulation during the Miocene in the Indian radiation is intriguing and contrary to our expectation. Further examination of the evolution of these microhabitat specific species could shed light on this apparent paradox.

\section{Conclusion}

We tested whether the EOC or late Miocene aridification could have facilitated the diversification of dry habitat diversity of Hemidactylus geckos using a hypothesis testing framework. The two climatic hypotheses predict that the shift in climate should overlap with the evolution of a dry habitat ancestor and an increase in diversification rate. Results from both ancestral state reconstruction and diversification analyses allow us to reject the late Miocene aridification hypothesis. Furthermore, the role of EOC in generating the dry habitat diversity of Hemidactylus geckos in Peninsular India cannot be rejected. The Indian radiation of Hemidactylus geckos, being the oldest known radiation among the dry zone reptiles of Peninsular India, suggests a much older date for the establishment of the dry climatic regime in Peninsular India. This study, consistent with the palynological work, strongly points towards presence of dry habitats in Peninsular India during the 
late Eocene-early Oligocene.

\section{Funding statement}

The molecular work was supported by Department of Science and Technology, Govt. of India, India through the grant SB/SO/AS-076/ 2013 to PK. Fieldwork was funded by The Rufford Small Grants Foundation Ref. No. 15328-1 to AL.

\section{Declaration of Competing Interest}

None.

\section{Acknowledgments}

We thank Tarun Singh, Chandra, Ishan Agarwal, Aniruddha DattaRoy, Varad Giri, Deepak Veerappan, Chaitanya K, Ushaprabha Page, Navendu Page, Kulbhushan Suryavanshi and family, S. K. Dutta, Caleb Daniels, Akshay Khandekar, Harshal Bhosale, Kiran Rahalkar, Pratik Talwar, Prasad Shinde, Ravindra Sonawane, Kalaimani, and Manjunath Reddy for their help with sample collection during fieldwork. Suranjan Karunarathna and Nature Explorations and Education Team "NEET" for providing GPS locations for Sri Lankan Hemidactylus. Maitreya Sil, Viraj Torsekar, and Navendu Page for useful discussion and comments on the manuscript. Liam Revell's course on 'Using R to study macroevolution in phylogenies' at transmitting science was beneficial and his continued help with analyses and troubleshooting is much appreciated. Forest departments of Andhra, Telangana, and Karnataka for their support during fieldwork. Rufford Small Grants for Nature Conservation funding that enabled the fieldwork and Asian Nature Conservation Foundation for their help in managing the funding. We thank all the reviewers for their valuable comments that improved the manuscript considerably.

\section{Appendix A. Supplementary material}

Supplementary data to this article can be found online at https:// doi.org/10.1016/j.ympev.2019.106637.

\section{References}

Abels, H.A., Dupont-Nivet, G., Xiao, G., Bosboom, R., Krijgsman, W., 2010. Step-wise change of Asian interior climate preceding the Eocene-Oligocene Transition (EOT). Palaeogeog. Palaeoclim. Palaeoecol. 299, 399-412. https://doi.org/10.1016/j. palaeo.2010.11.028.

Agarwal, I., Bauer, A.M., Giri, V.B., Khandekar, A., 2019. An expanded ND2 phylogeny of the brookii and prashadi groups with the description of three new Indian Hemidactylus Oken (Squamata: Gekkonidae). Zootaxa 4619, 431-458. https://doi. org/10.11646/zootaxa.4619.3.2.

Agarwal, I., Bauer, A.M., Jackman, T.R., Karanth, K.P., 2014a. Insights into Himalayan biogeography from geckos: a molecular phylogeny of Cyrtodactylus (Squamata: Gekkonidae). Mol. phylogenet. Evol. 80, 145-155. https://doi.org/10.1016/j.ympev. 2014.07.018.

Agarwal, I., Bauer, A.M., Jackman, T.R., Karanth, K.P., 2014b. Cryptic species and Miocene diversification of Palaearctic naked-toed geckos (Squamata: Gekkonidae) in the Indian dry zone. Zool. Scr. 43, 455-471. https://doi.org/10.1111/zsc.12062.

Agarwal, I., Giri, V.B., Bauer, A.M., 2011. A new cryptic rock-dwelling Hemidactylus (Squamata: Gekkonidae) from south India. Zootaxa 2765, 21-37. https://doi.org/10. 11646/zootaxa.2765.1.2.

Agarwal, I., Karanth, K.P., 2015. A phylogeny of the only ground-dwelling radiation of Cyrtodactylus (Squamata, Gekkonidae): diversification of Geckoella across peninsular India and Sri Lanka. Mol. phylogenet. Evol. 82, 193-199. https://doi.org/10.1016/j. ympev.2014.09.016.

Agarwal, I., Ramakrishnan, U., 2017. A phylogeny of open-habitat lizards (Squamata: Lacertidae: Ophisops) supports the antiquity of Indian grassy biomes. J. Biogeogr. 82, 193-212. https://doi.org/10.1111/jbi.12999.

Bansal, R., Karanth, K.P., 2013. Phylogenetic analysis and molecular dating suggest that Hemidactylus anamallensis is not a member of the Hemidactylus radiation and has an ancient Late Cretaceous origin. PLoS One 8, e60615. https://doi.org/10.1371/ journal.pone.0060615.

Bansal, R., Karanth, K.P., 2010. Molecular phylogeny of Hemidactylus geckos (Squamata: Gekkonidae) of the Indian subcontinent reveals a unique Indian radiation and an Indian origin of Asian house geckos. Mol. phylogenet. Evol. 57, 459-465. https://doi. org/10.1016/j.ympev.2010.06.008.

Bauer, A.M., Giri, V.B., Greenbaum, E., Jackman, T.R., 2008. On the systematics of the gekkonid genus Teratolepis Günther, 1869: another one bites the dust. Hamadryad 33, 13-27.

Bauer, A.M., Jackman, T.R., Greenbaum, E., de Silva, A., Giri, V.B., Das, I., 2010a. Molecular evidence for the taxonomic status of Hemidactylus brookii group taxa (Squamata: Gekkonidae). Herpetol. J. 20, 129-138.

Bauer, A.M., Jackman, T.R., Greenbaum, E., Giri, V.B., de Silva, A., 2010b. South Asia supports a major endemic radiation of Hemidactylus geckos. Mol. phylogenet. Evol. 57, 343-352. https://doi.org/10.1016/j.ympev.2010.06.014.

Becerra, J.X., 2005. Timing the origin and expansion of the Mexican tropical dry forest. Proc. Natl. Acad. Sci. USA 102, 10919-10923. https://doi.org/10.1073/pnas. 0409127102.

Brennan, I.G., Oliver, P.M., 2017. Mass turnover and recovery dynamics of a diverse Australian continental radiation. Evolution 71, 1352-1365. https://doi.org/10.1111/ evo.13207.

Burbrink, F.T., Chen, X., Myers, E.A., Brandley, M.C., Pyron, R.A., 2012. Evidence for determinism in species diversification and contingency in phenotypic evolution during adaptive radiation. Proc. Biol. Sci. 279, 4817-4826. https://doi.org/10.1098/ rspb.2012.1669.

Byrne, M., Steane, D.A., Joseph, L., Yeates, D., Jordan, G., Crayn, D., Aplin, K., Cantrill, D., Cook, L., Crisp, M., Keogh, S., Melville, J., Sunnucks, P., Weston, P., 2011. Decline of a biome: evolution, contraction, fragmentation, extinction and invasion of the Australian mesic zone biota. J. Biogeogr. 38, 1635-1656. https://doi.org/10.1111/j. 1365-2699.2011.02535.x/pdf.

Carranza, S., Arnold, E.N., 2006. Systematics, biogeography, and evolution of Hemidactylus geckos (Reptilia: Gekkonidae) elucidated using mitochondrial DNA sequences. Mol. phylogenet. Evol. 38, 531-545. https://doi.org/10.1016/j.ympev. 2005.07.012.

Cerling, T.E., Harris, J.M., MacFadden, B.J., Leakey, M.G., Quade, J., Eisenmann, V., Ehleringer, J.R., 1997. Global vegetation change through the Miocene/Pliocene boundary. Nature 389, 153-158. https://doi.org/10.1038/38229.

Chaitanya, R., Lajmi, A., Giri, V.B., 2018. A new cryptic, rupicolous species of Hemidactylus Oken, 1817 (Squamata: Gekkonidae) from Meghamalai, Tamil Nadu, India. Zootaxa 4374, 49-122. https://doi.org/10.11646/zootaxa.4374.1.3.

Clift, P.D., Hodges, K.V., Heslop, D., Hannigan, R., Van Long, H., Calves, G., 2008. Correlation of Himalayan exhumation rates and Asian monsoon intensity. Nat. Geosci. 1, 875-880.

Cyriac, V.P., Kodandaramaiah, U., 2017. Paleoclimate determines diversification patterns in the fossorial snake family Uropeltidae Cuvier, 1829. Mol. phylogenet. Evol. 116, 97-107. https://doi.org/10.1016/j.ympev.2017.08.017.

Dandge, P.H., Tiple, A.D., 2015. A new species of rupicolus gecko of the genus Hemidactylus Oken, 1817 (Reptilia: Squamata: Gekkonidae) from Maharashtra, central India. Russ. J. Herpetol 22.

Davis, C.C., Webb, C.O., Wurdack, K.J., Jaramillo, C.A., Donoghue, M.J., 2005. Explosive radiation of Malpighiales supports a mid-cretaceous origin of modern tropical rain forests. Am. Nat. 165, E36-E65. https://doi.org/10.1086/428296.

Deepak, V., Karanth, K.P., 2018. Aridification driven diversification of fan-throated lizards from the Indian subcontinent. Mol. Phylogenet. Evol. 120, 53-62. https://doi. org/10.1016/j.ympev.2017.11.016.

Donoghue, M.J., Edwards, E.J., 2014. Biome shifts and niche evolution in plants. Annu. Rev. Ecol. Evol. Syst. 45, 547-572. https://doi.org/10.1146/annurev-ecolsys120213-091905.

Drummond, A.J., Suchard, M.A., Xie, D., Rambaut, A., 2012. Bayesian phylogenetics with BEAUti and the BEAST 1.7. Mol. Biol. Evol. 29, 1969-1973. https://doi.org/10.1093/ molbev/mss075.

Dupont-Nivet, G., Krijgsman, W., Langereis, C.G., Abels, H.A., Dai, S., Fang, X., 2007. Tibetan plateau aridification linked to global cooling at the Eocene-Oligocene transition. Nature 445, 635-638. https://doi.org/10.1038/nature05516.

Edwards, E.J., Osborne, C.P., Strömberg, C.A.E., Smith, S.A., C4 Grasses Consortium, Bond, W.J., Christin, P.-A., Cousins, A.B., Duvall, M.R., Fox, D.L., Freckleton, R.P., Ghannoum, O., Hartwell, J., Huang, Y., Janis, C.M., Keeley, J.E., Kellogg, E.A., Knapp, A.K., Leakey, A.D.B., Nelson, D.M., Saarela, J.M., Sage, R.F., Sala, O.E., Salamin, N., Still, C.J., Tipple, B., 2010. The origins of C4 grasslands: integrating evolutionary and ecosystem science. Science 328, 587-591. doi: http://doi.org/10. 1126/science.1177216.

Edwards, E.J., Smith, S.A., 2009. Phylogenetic analyses reveal the shady history of C4 grasses Proc. Natl. Acad. Sci. 107, 2532-2537. https://doi.org/10.1073/pnas. 0909672107.

Erwin, D.H., 2009. Climate as a driver of evolutionary change. Curr. Biol. 19, R575-R583. https://doi.org/10.1016/j.cub.2009.05.047.

Etienne, R.S., Haegeman, B., 2012. A conceptual and statistical framework for adaptive radiations with a key role for diversity dependence. Am. Nat. https://doi.org/10. 5061/dryad.sr927n43.

Ezard, T.H.G., Aze, T., Pearson, P.N., Purvis, A., 2011. Interplay between changing climate and species' ecology drives macroevolutionary dynamics. Science 332, 349-351. https://doi.org/10.1126/science.1203060.

Fick, S.E., Hijmans, R.J., 2017. WorldClim 2: New 1-km spatial resolution climate surfaces for global land areas. Int. J. Climatol. 37, 4302-4315. https://doi.org/10.1002/ joc. 5086 .

Fordyce, J.A., 2010. Interpreting the $\gamma$ statistic in phylogenetic diversification rate studies: A rate decrease does not necessarily indicate an early burst. PLoS One 5, e11781-e11785. https://doi.org/10.1371/journal.pone.0011781.

Fortelius, M., Eronen, J., Liu, L., Pushkina, D., Tesakov, A., Vislobokova, I., Zhang, Z., 2006. Late Miocene and Pliocene large land mammals and climatic changes in Eurasia. Palaeogeog. Palaeoclim. Palaeoecol. 238, 219-227. https://doi.org/10. 
1016/j.palaeo.2006.03.042

Gaikwad, K.S., Kulkarni, H., Bhambure, R., Giri, V.B., 2009. Notes on the distribution, natural history and variation of Hemidactylus albofasciatus (Grandison and Soman, 1963) (Squamata: Gekkonidae). J. Bombay Nat. History Soc. 106, 305.

Gamble, T., Greenbaum, E., Jackman, T.R., Russell, A.P., Bauer, A.M., 2012. Repeated origin and loss of adhesive toepads in geckos. PLoS One 7, e39429. https://doi.org/ 10.1371/journal.pone.0039429.

Gamble, T., Simons, A.M., Colli, G.R., Vitt, L.J., 2008. Tertiary climate change and the diversification of the Amazonian gecko genus Gonatodes (Sphaerodactylidae, Squamata). Mol. phylogenet. Evol. 46, 269-277. https://doi.org/10.1016/j.ympev. 2007.08.013.

Giri, V., Bauer, A., 2006. Notes on the distribution, natural history and variation of Hemidactylus prashadi Smith, 1935. Hamadryad 30, 55.

Giri, V.B., 2008. A new rock-dwelling Hemidactylus (Squamata: Gekkonidae) from Maharashtra, India. Hamadryad 32, 25-33.

Giri, V.B., Bauer, A.M., 2008. A new ground-dwelling Hemidactylus (Squamata: Gekkonidae) from Maharashtra, with a key to the Hemidactylus of India. Zootaxa $1700,21-34$.

Giri, V.B., Bauer, A.M., Mohapatra, P.P., Srinivasulu, C., Agarwal, I., 2017. A new species of large-bodied, tuberculate Hemidactylus Oken (Squamata: Gekkonidae) from the Eastern Ghats, India. Zootaxa 4347, 331. https://doi.org/10.11646/zootaxa.4347. 2.8 .

Gower, D.J., Agarwal, I., Karanth, K.P., Datta-Roy, A., Giri, V.B., Wilkinson, M., San Mauro, D., 2016. The role of wet-zone fragmentation in shaping biodiversity patterns in peninsular India: insights from the caecilian amphibian Gegeneophis. J. Biogeogr. 43, 1091-1102. https://doi.org/10.1111/jbi.12710.

Harmon, L.J., Weir, J.T., Brock, C.D., Glor, R.E., Challenger, W., 2008. GEIGER: investigating evolutionary radiations. Bioinformatics $24,129-131$. https://doi.org/10. 1093/bioinformatics/btm538.

Heinicke, M.P., Greenbaum, E., Jackman, T.R., Bauer, A.M., 2011. Phylogeny of a transWallacean radiation (Squamata, Gekkonidae, Gehyra) supports a single early colonization of Australia. Zoologica Scripta 40, 584-602.

Hoorn, C., Straathof, J., Abels, H.A., Xu, Y., Utescher, T., Dupont-Nivet, G., 2012. A late Eocene palynological record of climate change and Tibetan Plateau uplift (Xining Basin, China). Palaeogeog. Palaeoclim. Palaeoecol. 344-345, 16-38. https://doi.org/ 10.1016/j.palaeo.2012.05.011.

Hren, M.T., Sheldon, N.D., Grimes, S.T., Collinson, M.E., Hooker, J.J., Bugler, M., Lohmann, K.C., 2013. Terrestrial cooling in Northern Europe during the Eocene-Oligocene transition. Proc. Natl. Acad. Sci. USA 110, 7562-7567. https://doi. org/10.1073/pnas.1210930110.

Huang, J.P., Knowles, L.L., 2016. The species versus subspecies conundrum: quantitative delimitation from integrating multiple data types within a single Bayesian approach in Hercules beetles. Syst. Biol. 65, 685-699. https://doi.org/10.1093/sysbio/syv119.

Ivany, L.C., Patterson, W.P., Lohmann, K.C., 2000. Cooler winters as a possible cause of mass extinctions at the Eocene/Oligocene boundary. Nature 407, 887-890. https:// doi.org/10.1038/35038044.

Kapli, P., Lutteropp, S., Zhang, J., Kobert, K., Pavlidis, P., Stamatakis, A., Flouri, T., Valencia, A., 2017. Multi-rate Poisson tree processes for single-locus species delimitation under maximum likelihood and Markov chain Monte Carlo. Bioinformatics 33, 1630-1638. https://doi.org/10.1093/bioinformatics/btx025.

Karanth, K.P., 2003. Evolution of disjunct distributions among wet-zone species of the Indian subcontinent. Curr. Sci. 85, 1276-1283.

Kargaranbafghi, F., Neubauer, F., 2017. Tectonic forcing to global cooling and aridification at the Eocene-Oligocene transition in the Iranian plateau. Global Planet. Change. https://doi.org/10.1016/j.gloplacha.2017.12.012.

Lajmi, A., Bansal, R., Giri, V., Karanth, K.P., 2019. Phylogeny and biogeography of the endemic Hemidactylus geckos of the Indian subregion suggest multiple dispersals from Peninsular India to Sri Lanka. Zool. J. Linn. Soc. 186, 286-301.

Lajmi, A., Giri, V.B., Karanth, K.P., 2016. Molecular data in conjunction with morphology help resolve the Hemidactylus brookii complex (Squamata: Gekkonidae). Org. Divers. Evol. 16, 659-677. https://doi.org/10.1007/s13127-016-0271-9.

Lanfear, R., Calcott, B., Ho, S.Y.W., Guindon, S., 2012. PartitionFinder: Combined selection of partitioning schemes and substitution models for phylogenetic analyses. Mol. Biol. Evol. 29, 1695-1701. https://doi.org/10.1093/molbev/mss020.

Leache, A.D., Fujita, M.K., 2010. Bayesian species delimitation in West African fores geckos (Hemidactylus fasciatus). Proc. Biol. Sci. 277, 3071-3077. https://doi.org/10. 1086/386552.

Marin, J., Donnellan, S.C., Blair Hedges, S., Doughty, P., Hutchinson, M.N., Cruaud, C., Vidal, N., 2013. Tracing the history and biogeography of the Australian blindsnake radiation. J. Biogeogr. 40, 928-937. https://doi.org/10.1111/jbi.12045.

Mayhew, P.J., Jenkins, G.B., Benton, T.G., 2008. A long-term association between global temperature and biodiversity, origination and extinction in the fossil record. Proc. Biol. Sci. 275, 47-53. https://doi.org/10.1098/rspb.2007.1302.

Meng, J., McKenna, M.C., 1998. Faunal turnovers of Palaeogene mammals from the Mongolian Plateau. Taprobanica 394, 364-367.

Mirza, Z., Sanap, R., 2014. A new cryptic species of gecko of the genus Hemidactylus Oken 1817 (Reptilia: Gekkonidae) from southern India. Taprobanica 06, 12-20.

Mirza, Z.A., 2018. A new cryptic species of ground-dwelling Hemidactylus (Squamata: Gekkonidae) from southern India. Phyllomedusa 17, 169-180. https://doi.org/10. 11606/issn.2316-9079.v17i2p169-180.

Mirza, Z.A., Bhosale, H., Patil, R., 2017. A new large species of gecko of the genus Hemidactylus Oken, 1817 (Reptilia: Sauria: Gekkonidae) from the Eastern Ghats, India. Comptes Rendus Biologies 1-11. https://doi.org/10.1016/j.crvi.2017.09.003.

Mirza, Z.A., Gowande, G.G., Patil, R., Ambekar, M., Patel, H., 2018. First appearance deceives many: disentangling the Hemidactylus triedrus species complex using an in tegrated approach. PeerJ 6, e5341-e5435. https://doi.org/10.7717/peerj.5341.
Mirza, Z.A., Raju, D., 2017. A new rupicolous species of gecko of the genus Hemidactylus Oken, 1817 from the Satpura Hills, Central India. Amphib. Reptile Conse. 11, 51-71.

Molnar, P., Rajagopalan, B., 2012. Late Miocene upward and outward growth of eastern Tibet and decreasing monsoon rainfall over the northwestern Indian subcontinent since 10 Ma. Geophys. Res. Lett. doi: http://doi.org/10.1029/2012GL051305.

Morley, R., 2000. Origin and Evolution of Tropical Rain Forests. John Wiley \& Sons.

Murthy, B.H.C.K., Bauer, A., Lajmi, A., Agarwal, I., Giri, V.B., 2014. A new rock dwelling Hemidactylus (Squamata: Gekkonidae) from Chhattisgarh, India. Zootaxa 4021, 334-350. https://doi.org/10.11646/zootaxa.4021.2.5.

Nielsen, S.V., Bauer, A.M., Jackman, T.R., Hitchmough, R.A., Daugherty, C.H., 2011. New Zealand geckos (Diplodactylidae): Cryptic diversity in a post-Gondwanan lineage with trans-Tasman affinities. Mol. phylogenet. Evol. 59, 1-22. https://doi.org/10. 1016/j.ympev.2010.12.007.

Oliver, P.M., Hugall, A.F., 2017. Phylogenetic evidence for mid-Cenozoic turnover of a diverse continental biota. Nat. Ecol. Evol. 1, 1896-1902. https://doi.org/10.1038/ s41559-017-0355-8.

Passchier, S., Bohaty, S.M., Jiménez Espejo, F., Pross, J., Röhl, U., Flierdt, T., Escutia, C., Brinkhuis, H., 2013. Early Eocene to middle Miocene cooling and aridification of East Antarctica. Geochem. Geophy. Geosyst. 14, 1399-1410. https://doi.org/10.1002/ ggge.20106.

Pennington, R.T., Richardson, J.E., Lavin, M., 2006. Insights into the historical construction of species-rich biomes from dated plant phylogenies, neutral ecological theory and phylogenetic community structure. New Phytol. 172, 605-616. https:// doi.org/10.1111/j.1469-8137.2006.01902.x.

Phillimore, A.B., Price, T.D., 2008. Density-dependent cladogenesis in birds. Plos. Biol. 6, e71. https://doi.org/10.1371/journal.pbio.0060071.st002.

Pound, M.J., Haywood, A.M., Salzmann, U., Riding, J.B., 2012. Global vegetation dynamics and latitudinal temperature gradients during the Mid to Late Miocene (15.97-5.33 Ma). Earth-Science Rev. 112, 1-22. https://doi.org/10.1016/j.earscirev. 2012.02.005.

Powney, G.D., Grenyer, R., Orme, C.D.L., Owens, I.P.F., Meiri, S., 2010. Hot, dry and different: Australian lizard richness is unlike that of mammals, amphibians and birds. Global Ecol. Biogeogr. 19, 386-396. https://doi.org/10.1111/j.1466-8238.2009. 00521.x.

Prasad, V., Farooqui, A., Tripathi, S.K.M., Garg, R., Thakur, B., 2009. Evidence of late Palaeocene-early Eocene equatorial rain forest refugia in southern Western Ghats, India. J. Biosci. 34, 777-797.

Prothero, D.R., 1994. The late Eocene-Oligocene extinctions. Annu. Rev. Earth Planet Sci. 22, 145-165. https://doi.org/10.1146/annurev.ea.22.050194.001045.

Prothero, D.R., Berggren, W.A., 2014. Eocene-Oligocene Climatic and Biotic Evolution. Princeton University Press.

Pybus, O.G., Harvey, P.H., 2000. Testing macro-evolutionary models using incomplete molecular phylogenies. Proc. Biol. Sci. 267, 2267-2272. https://doi.org/10.1098/ rspb.2000.1278.

Pyron, R., Burbrink, F.T., Wiens, J.J., 2013. A phylogeny and revised classification of Squamata, including 4161 species of lizards and snakes. BMC Evol. Biol. 13, 93. https://doi.org/10.1186/1471-2148-13-93.

Rabosky, D.L., 2013. Diversity-dependence, ecological speciation, and the role of competition in macroevolution. Annu. Rev. Ecol. Evol. Syst. 44, 481-502. https://doi. org/10.1146/annurev-ecolsys-110512-135800.

Rabosky, D.L., Hurlbert, A.H., 2015. Species richness at continental scales is dominated by ecological limits. Am. Nat. 185, 572-583. https://doi.org/10.1086/680850.

Rabosky, D.L., Lovette, I.J., 2008a. Density-dependent diversification in North American wood warblers. Proc. Biol. Sci. 275, 2363-2371. https://doi.org/10.1098/rspb.2008. 0630 .

Rabosky, D.L., Lovette, I.J., 2008b. Explosive evolutionary radiations: decreasing speciation or increasing extinction through time? Evolution 62, 1866-1875. https://doi org/10.1111/j.1558-5646.2008.00409.x.

Revell, L.J., 2012. phytools: An R package for phylogenetic comparative biology (and other things). Methods Ecol. Evol. 3, 217-223. https://doi.org/10.1111/j.2041210X.2011.00169.x/full.

Richardson, J.E., Weitz, F.M., Fay, M.F., Cronk, Q.C.B., Linder, H.P., Reeves, G., Chase, M.W., 2001. Rapid and recent origin of species richness in the Cape flora of South Africa. Nature 412, 35084067-35084183. https://doi.org/10.1038/35084067.

Roll, U., Feldman, A., Novosolov, M., Allison, A., Bauer, A.M., Bernard, R., Böhm, M., Castro-Herrera, F., Chirio, L., Ben Collen, Colli, G.R., Dabool, L., Das, I., Doan, T.M., Grismer, L.L., Hoogmoed, M., Itescu, Y., Kraus, F., LeBreton, M., Lewin, A., Martins, M., Maza, E., Meirte, D., Nagy, Z.T., de C Nogueira, C., Pauwels, O.S.G., PincheiraDonoso, D., Powney, G.D., SINDACO, R., Tallowin, O.J.S., Torres-Carvajal, O., Trape, J.-F., Vidan, E., Uetz, P., Wagner, P., Wang, Y., Orme, C.D.L., Grenyer, R., Meiri, S., 2017. The global distribution of tetrapods reveals a need for targeted reptile conservation. Nat Ecol. Evol. 1, 1677-1682. doi: http://doi.org/10.1038/s41559-017 0332-2.

Ronquist, F., Teslenko, M., van der Mark, P., Ayres, D.L., Darling, A., Höhna, S., Larget, B., Liu, L., Suchard, M.A., Huelsenbeck, J.P., 2012. MrBayes 3.2: efficient Bayesian phylogenetic inference and model choice across a large model space. Syst. Biol. 61, 539-542. https://doi.org/10.1093/sysbio/sys029.

Silvestro, D., Michalak, I., 2012. raxmlGUI: a graphical front-end for RAxML. Org. Divers. Evol. 12, 335-337. https://doi.org/10.1007/s13127-011-0056-0.

Champion, S.H., Seth, S.K. 1968. A revised survey of the forest types of India.

Srikanthan, A.N., Swamy, P., Mohan, A.V., Pal, S., 2018. A distinct new species of riparian rock-dwelling gecko (Genus: Hemidactylus) from the southern Western Ghats. Zootaxa 4434, 141-217. https://doi.org/10.11646/zootaxa.4434.1.9.

Srinivasulu, C., Srinivasulu, A., Kumar, G.C., 2018. A new cryptic rock-dwelling Hemidactylus Oken, 1817 (Squamata: Gekkonidae) from northern Karnataka, India. Zootaxa 4444, 25-42. https://doi.org/10.11646/zootaxa.4444.1.2. 
Srinivasulu, C., Srinivasulu, B., Molur, S., 2014. The Status and Distribution of Reptiles in the Western Ghats, India. Wildlife Information Laision Development Society,

Coimbatore, Tamil Nadu, Conservation assessment and management plan (CAMP).

Stadler, T., 2011. Mammalian phylogeny reveals recent diversification rate shifts. Proc. Natl. Acad. Sci. USA 108, 6187-6192. https://doi.org/10.1073/pnas.1016876108.

Stamatakis, A., 2006. RAxML-VI-HPC: maximum likelihood-based phylogenetic analyses with thousands of taxa and mixed models. Bioinformatics 22, 2688-2690. https:// doi.org/10.1093/bioinformatics/btl446.

Sun, J., Ni, X., Bi, S., Wu, W., Ye, J., Meng, J., Windley, B.F., 2014. Synchronous turnover of flora, fauna, and climate at the Eocene-Oligocene Boundary in Asia. Sci. Rep. 4, 1. https://doi.org/10.1038/srep07463.

Tamura, K., Peterson, D., Peterson, N., Stecher, G., Nei, M., Kumar, S., 2011. MEGA5: molecular evolutionary genetics analysis using maximum likelihood, evolutionary distance, and maximum parsimony methods. Mol. Biol. Evol. 28, 2731-2739. https:// doi.org/10.1093/molbev/msr121.

Tang, Z.-H., Ding, Z.-L., 2013. A palynological insight into the Miocene aridification in the Eurasian interior. Palaeoworld 22, 77-85. https://doi.org/10.1016/j.palwor. 2013.05.001.

R Core Team, 2014. R: A Language and Environment for Statistical Computing. Austria R Foundation for Statistical Computing, Vienna.

Thompson, J.D., Higgins, D.G., Gibson, T.J., 1994. CLUSTAL W: Improving the sensitivity of progressive multiple sequence alignment through sequence weighting, positionspecific gap penalties and weight matrix choice. Nucleic Acids Res. 22, 4673-4680.

Vijayakumar, S.P., Menezes, R.C., Jayarajan, A., Shanker, K., 2016. Glaciations, gradients, and geography: multiple drivers of diversification of bush frogs in the Western Ghats Escarpment. Proc. Biol. Sci. 283. https://doi.org/10.1098/rspb.2016.1011.

Wade, B.S., Houben, A.J.P., Quaijtaal, W., Schouten, S., Rosenthal, Y., Miller, K.G., Katz, M.E., Wright, J.D., Brinkhuis, H., 2012. Multiproxy record of abrupt sea-surface cooling across the Eocene-Oligocene transition in the Gulf of Mexico. Geol. 40, 159-162. https://doi.org/10.1130/G32577.1.

Wagner, C.E., Harmon, L.J., Seehausen, O., 2014. Cichlid species-area relationships are shaped by adaptive radiations that scale with area. Ecol. Lett. 17, 583-592. https:// doi.org/10.1111/ele.12260.

Wiens, J.J., Kozak, K.H., Silva, N., 2013. Diversity and niche evolution along aridity gradients in North American lizards (Phrynosomatidae). Evolution 67, 1715-1728. https://doi.org/10.1111/evo.12053.

Yang, Z., 2015. The BPP program for species tree estimation and species delimitation. Curr. Zool. 61, 854-865. https://doi.org/10.1093/czoolo/61.5.854.

Yang, Z., Rannala, B., 2014. Unguided species delimitation using DNA sequence data from multiple Loci. Mol. Biol. Evol. 31, 3125-3135. https://doi.org/10.1093/molbev/ msu279.

Zachos, J., Pagani, M., Sloan, L., Thomas, E., Billups, K., 2001. Trends, rhythms, and aberrations in global climate 65 Ma to present. Science 292, 686-693. https://doi. org/10.1126/science.1059412.

Zhang, R., Kravchinsky, V.A., Yue, L., 2012. Link between global cooling and mammalian transformation across the Eocene-Oligocene boundary in the continental interior of Asia. Int. J. Earth. Sci. 101, 2193-2200. 